\title{
DISCUSSION
}

\section{Improvement of granular soils by high-energy impacts}

\author{
Y. K. CHOW, D. M. YONG, K. M. YONG and S. L. LEE (2000) Ground \\ Improvement, 4, No. 1, 31-35
}

\section{J. A. Howie and Ali Amini Asalemi, Department of Civil Engineering, University of British Columbia, Vancouver}

The authors have presented very interesting results showing excellent agreement between those predicted by the authors' model (Chow et al., 1992) and the measured crater depths obtained in several case histories of dynamic compaction (DC). The paper indicates that the input parameters for the soil model are obtained by correlation with the tip resistance $\left(\boldsymbol{q}_{\mathrm{c}}\right)$ obtained from electric cone penetration testing (CPT). The authors present a number of figures in terms of relative density $\left(D_{\mathrm{r}}\right)$ against depth before and after ground treatment. The numerical model appears to calculate changes in $D_{\mathrm{r}}$ from an initial value interpreted from cone penetration tip resistance. The final value of $D_{\mathrm{r}}$ predicted by the model also appears to agree very closely with the value of $D_{\mathrm{r}}$ obtained by correlation with CPT testing conducted after the first pass of DC. This agreement is surprising for the reasons now outlined.

Cone penetration testing under controlled conditions in calibration chambers has shown that the correlation between $\boldsymbol{q}_{\mathrm{c}}$ and $D_{\mathrm{r}}$ is very dependent on the in situ lateral stress (e.g. Houlsby and Hitchman, 1988). Baldi et al. (1986) recommended the following formula to estimate relative density based on calibration chamber test data:

$$
D_{\mathrm{r}}=\frac{1}{\mathrm{C}_{2}} \ln \left(-\frac{\boldsymbol{q}_{\mathrm{c}}}{\mathrm{C}_{\mathrm{p}}\left(\boldsymbol{\sigma}^{\prime}\right)^{\mathrm{C}_{2}}}\right)
$$

where $C_{0}, C_{1}$ and $C_{2}$ are soil constants with values of 181 , 0.55 and 2.61 respectively; $\boldsymbol{\sigma}^{\prime}$ is the mean effective stress in $\mathrm{kPa}$; and $\boldsymbol{q}_{\mathrm{c}}$ is the cone penetration resistance in $\mathrm{kPa}$. At a vertical effective stress of $40 \mathrm{kPa}$, this formula predicts that a cone tip resistance of $8 \mathrm{MPa}$ will indicate a $D_{\mathrm{r}}$ of $75 \%$ for $K_{0}=0.5$ and $62 \%$ for a $K_{0}=1.5$.

In their 1992 paper, Chow et al. noted that DC changed the lateral stress. It seems likely that the change in lateral stress will be greater near the ground surface than at depth-that is, $K_{0}$ will decrease with depth, approaching the normally consolidated condition at a depth which will depend on the energy input during DC. As the authors' model seems to include correlations with soil parameters selected based on the estimated $D_{\mathrm{r}}$, it would seem important that this effect be taken into account.

It would be appreciated if the authors would indicate whether their model is sensitive to this effect and whether they account for changes in lateral stress when:

(a) updating soil properties in the model

(b) interpreting the $D_{\mathrm{r}}$ profile from the post-densification $\mathrm{CPT}$ results for comparison with analysis results.
In addition, it would be useful if the authors would give some guidance as to the basis for selection of foundation design parameters for the treated ground. Would their model give an estimate of soil stiffness or would the design parameters also be selected based on the interpreted distribution of $D_{\mathrm{r}}$ with depth?

\section{Authors' reply}

The authors thank the discussers for their interest in the paper. As rightly pointed out by the discussers, the change in lateral stress will be greater near the ground surface than at depth during the improvement of the ground. This change in the lateral stress is taken into account in the numerical model in an approximate manner when updating the soil properties after the impact of the pounder. Interpreting the $D_{\text {r }}$ profile from the post-densification results is done by relating $D_{\mathrm{r}}$ to the residual strains in the soil column elements. The details of the procedure are given in Chow et al. (1992). It is recognized that this is an approximation but it is not possible to estimate these properties in a more rigorous manner using this simple model. It is noted that the computed pounder penetration, and degree and depth of soil improvement are essentially governed by the non-linear behaviour of the soil column, and are less sensitive to the updating of the soil parameters of the soil springs and dashpots.

The foundation design parameters for the treated ground may be selected based on the interpreted distribution of the friction angle and $D_{\mathrm{r}}$ with depth. It is noted that the numerical model only gives the design parameters directly beneath the pounder. Estimation of the lateral extent of the ground improvement can be estimated using the procedure reported in Chow et al. (1994). If the print spacing in the dynamic compaction scheme is such that the ground is not uniformly treated, some approximations will need to be made when using standard bearing capacity theories.

\section{References}

Baldi G., Bellotti R., Ghionna V. N., JAmiolkowsKi M. and PAsqualini E. (1986) Interpretation of CPT's and CPTU's second part: Drained penetration of sands. Proceedings of the 4 th International Geotechnical Seminar on Field Instrumentation and In Situ Measurements, Nan Yang Technical Institute, Singaport.

Chow Y. K., Yong D. M., Yong K. Y. and LeE S. L. (1992) Dynamic compaction analysis. Journal of Geotechnical Engineering, ASCE, 118, No. 8, 1141-1157. 
Chow Y. K., Yong D. M., Yong K. Y. and Lee S. L. (1992) Dynamic compaction of loose sand deposits. Soils and Foundations, 32, No. 4, 93-106.

Chow Y. K., Yong D. M., Yong K. Y. and Lee S. L. (1994) Dynamic compaction of loose granular soils: effect of print spacing. Journal of Geotechnical Engineering, ASCE, 120, No. 7, 1115-1133. Houlsby G. T. and Hitchman R. (1988) Calibration chamber tests of a cone penetrometer in sands. Géotechnique, 38, No. 1, 39-44. 